$10 / 3,2+9798(1)$

SANDIA REPORT

M97052279

SAND97-8216 • UC-406

Unlimited Release

Printed February 1997

\title{
CADMIUM ZINC TELLURIDE CHARGED PARTICLE NUCLEAR DETECTORS
}

J. E. Toney, R. B. James, J. Butler, P. Doty, T. E. Schlesinger,

B. A. Brunett, H. Yoon, J. M. Van Scyoc, J. Lund, A. Antolak,

R. W. Olsen, H. Hermon, D. H. Morse, M. Schieber, and R. H. Stulen

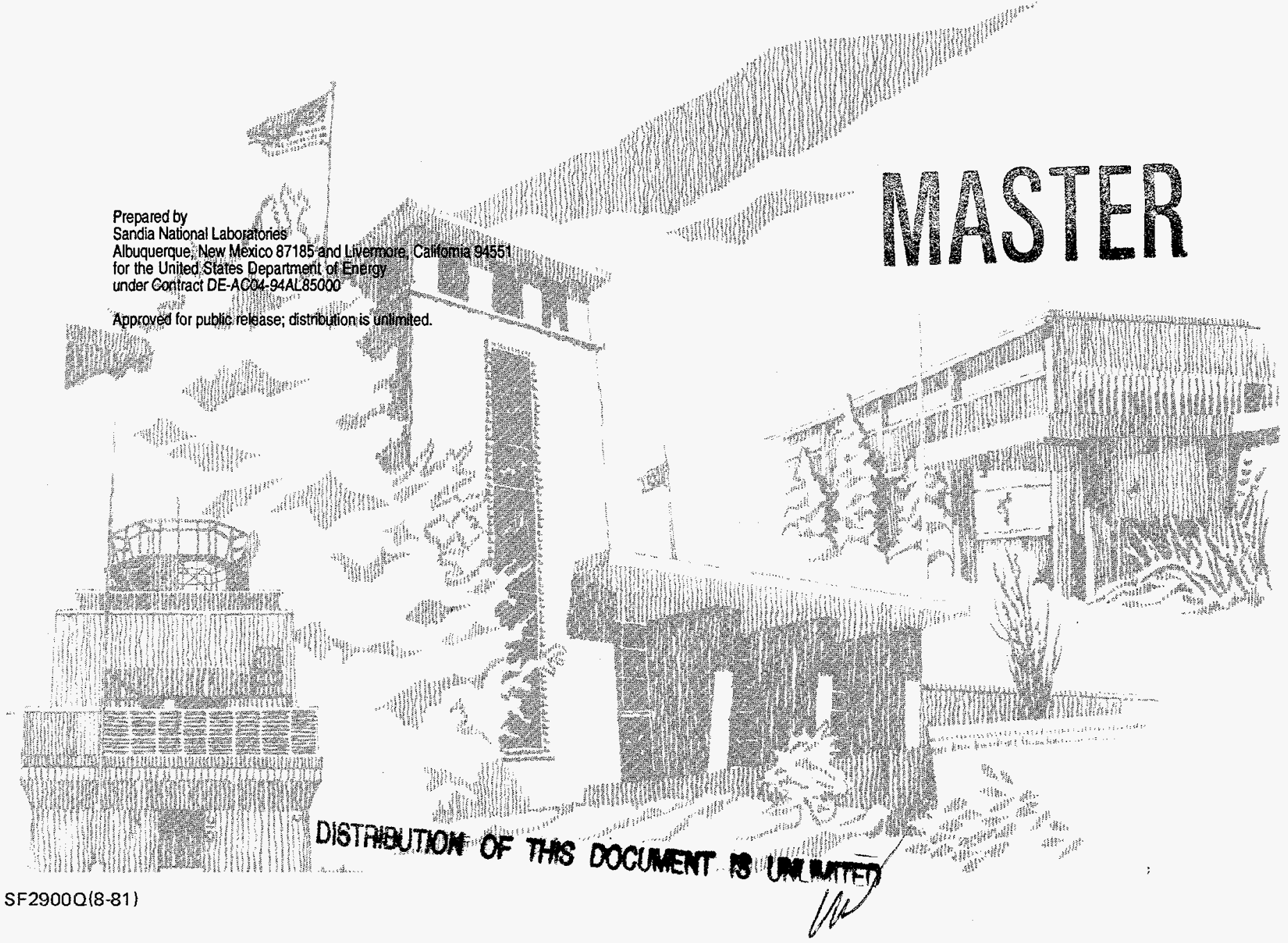


Issued by Sandia National Laboratories, operated for the United States Department of Energy by Sandia Corporation.

NOTICE: This report was prepared as an account of work sponsored by an agency of the United States Government. Neither the United States Government nor any agency thereof, nor any of their employees, nor any of the contractors, subcontractors, or their employees, makes any warranty, express or implied, or assumes any legal liability or responsibility for the accuracy, completeness, or usefulness of any information, apparalus, product, or process disclosed, or represents that its use would not infringe privately owned rights. Reference herein to any specific commercial product, process, or sevvice by trade name, trademark, manufacturer, or othenwise, does not necessarily constitute or imply its endorsement, recommendation, or favoring by the United States Government, any agency thereof or any of their contractors or subcontractors. The views and opinions expressed herein do not necessarily state or reflect those of the United States Government, any agency thereof, or any of their contractors or subcontractors.

This report has been reproduced from the best available copy.

Available to DOE and DOE contractors from:

Office of Scientific and Technical Information

P.O. Box 62

Oak Ridge TN 37831

Prices available from (615) 576-8401, FTS 626-8401.

Available to the public from:

National Technical Information Service

U.S. Department of Commerce

5285 Port Royal Rd.

Springfield, VA 22161 


\section{DISCLAIMER}

This report was prepared as an account of work sponsored by an agency of the United States Government. Neither the United States Government nor any agency thereof, nor any of their employees, make any warranty, express or implied, or assumes any legal liability or responsibility for the accuracy, completeness, or usefulness of any information, apparatus, product, or process disclosed, or represents that its use would not infringe privately owned rights. Reference herein to any specific commercial product, process, or service by trade name, trademark, manufacturer, or otherwise does not necessarily constitute or imply its endorsement, recommendation, or favoring by the United States Government or any agency thereof. The views and opinions of authors expressed herein do not necessarily state or reflect those of the United States Government or any agency thereof. 


\section{DISCLAMMER}

Portions of this document may be illegible in electronic image products. Images are produced from the best available original document. 
SAND97-8216

UC-406

Unlimited Release

Printed February 1997

\title{
Cadmium Zinc Telluride Charged Particle Nuclear Detectors
}

J.E. Toney ${ }^{1,2}$, R. B. James ${ }^{1}$, J. Butler ${ }^{3}$, P. Doty ${ }^{3}$, T.E. Schlesinger ${ }^{2}$, B. A. Brunett ${ }^{2}$, H. Yoon ${ }^{5,1}$, J. M. Van Scyoc ${ }^{1,5}$, J. Lund ${ }^{1}$, A. Antolak ${ }^{1}$, R. W. Olsen ${ }^{1}$, H. Hermon ${ }^{1}$, D. H. Morse ${ }^{1}$, M. Schieber ${ }^{1,4}$, and R. H. Stulen ${ }^{1}$

${ }^{1}$ Sandia National Laboratories, Livermore, CA 94551

${ }^{2}$ Carnegie Mellon University, Pittsburgh, PA 15213

${ }^{3}$ Digirad Corporation, San Diego, CA 92121

${ }^{4}$ The Hebrew University of Jerusalem, Jerusalem, Israel 91440

${ }^{5}$ University of California at Los Angeles, Los Angeles, CA 90024

\begin{abstract}
This report describes the improvements in understanding of transport phenomena in cadmium zinc telluride radiation sensors achieved through studies of alpha particle response and spatially resolved photoconductivity mapping. Alpha particle response waveforms and photocurrent profiles both indicate non-uniformities in the electric field which may have detrimental effects on detector performance. Identifying and eliminating the sources of these nonuniformities will ultimately lead to improved detector performance.
\end{abstract}




\section{Acknowledgment}

We gratefully acknowledge the support of the U.S. Department of Energy under contract number DE-AC04-94AL85000. In addition we would like to acknowledge the efforts of the various graduate students and researchers who have contributed to this effort and have helped to make this project a success. 


\section{Contents}

Preface.

Summary.

Nomenclature

Introduction.

Background.

Models of Transport Phenomena

Photoconductivity Mapping Studies.

Alpha Particle Response Studies

Conclusions.

References. 


\section{Preface}

The quality of cadmium zinc telluride ((Cd,Zn)Te or CZT) charged particle detectors is currently limited by the presence of impurities introduced by impure starting materials, crystal growth, and during device processing. These impurities act as carrier traps which reduce the charge collection in fabricated CZT sensors and degrade the performance of the instruments. Although the potential for fabricating high resolution charged particle detectors from CZT crystals has been clearly demonstrated, the quality of the detectors is still limited due to carrier trapping. The primary objective of the cooperation between Sandia and Digirad is to improve the performance of CZT alpha particle detectors by identifying and reducing the dominant carrier traps limiting the device performance. The resolution of this problem would drastically lower the cost of CZT instruments. Moreover, the availability of an inexpensive, portable charged particle and gamma-ray spectrometer that can both monitor the presence of radiation and identify the radioactive source would find a large range of new medical, industrial, environmental, scientific, and national security applications.

The ability to detect and perform energy-dispersive spectroscopy on incident alpha particles, $\mathrm{X}$-rays and gamma-rays is of great importance, since it makes possible a wide variety of analysis and imaging techniques that may have value both commercially as well as to DOE Defense Programs applications. However, the use of this technology has generally been limited to the laboratory since, in the past, the detectors and spectrometers that offered high resolution spectroscopic capabilities were limited to operation at cryogenic temperatures $(77 \mathrm{~K})$. These devices included lithium-drifted silicon and high purity germanium. Thus, the widespread application of these and other spectroscopic tools has been limited by the need for a cumbersome cooling apparatus and the constant attention these systems require. Size alone often impedes the use of these systems in some applications.

In recent years the technology of radiation detectors that operate at room temperature has greatly improved. The reason for this is that the ability to grow a number of semiconductor materials with the appropriate properties required for high performance 
spectrometers has been developed. Cadmium zinc telluride is a leading candidate because its high atomic number and large band gap make it particularly well suited for fabrication of compact spectrometers that can operate at room temperature. A great deal of effort has been dedicated to the growth of single-crystal, large volume cadmium zinc telluride which is high resistivity, highly uniform, stoichiometric, and has a minimum of structural and chemical defects. The material and electronic advances that have been made have permitted the production of systems operating at room temperature whose performance rivals that of cryogenically cooled systems in terms of energy resolution, signal-to-noise ratio, collection efficiency, and sensitivity. With the need for expensive and cumbersome cooling apparatus eliminated, these systems can be lightweight, even hand-held, and operate for long periods of time unattended. Some general purpose commercial systems capable of performing $\mathrm{x}$-ray fluorescence spectroscopy over a wide range of elements are now available, as are less expensive systems used for the identification of particular elements such as lead. Practical imaging systems operating at X-ray or gamma-ray energies are only a few years away from realization, and prototype systems have already been demonstrated.

However, one of the major obstacles to the widespread use of these CZT based systems has been the very low manufacturing yield, of only a few percent, of high resolution detectors. This has resulted in very high system costs. This low manufacturing yield has been a result of the presence of impurities and defects that have limited detector performance. These defects are introduced into the material during growth, contact deposition, or at various stages during detector fabrication. The object of this program was to obtain a fundamental understanding of the impact of trapping phenomena on the performance of CZT radiation detectors. The work that was performed to do this is described in this report. 


\section{Summary}

The objective of this project was to develop a means of studying transport properties of charge carriers in cadmium zinc telluride and their impact on performance of radiation detectors fabricated from the material. The role of the laboratory personnel and facilities was to coordinate and couple material and electrical engineering studies with device information obtained through the use of a wide variety of experimental analysis techniques. This work paralleled related efforts at Sandia supporting the development of improved cadmium zinc telluride detectors for national security applications. Variations in material quality and detector performance were investigated and this has lead to a better understanding of the distribution in the electric field in CZT detectors suitable for alpha particle detection. 


\section{Nomenclature}

CZT or $(\mathrm{Cd}, \mathrm{Zn}) \mathrm{Te}$
$\mathrm{Cd}_{1-\mathrm{x}} \mathrm{Zn}_{\mathrm{x}} \mathrm{Te}$
$\mathrm{NEST}$
$\mathrm{Z}$

Cadmium Zinc Telluride

Cadmium Zinc Telluride with molar zinc fraction of $x$

Nuclear Emergency Search Team atomic number 


\section{Cadmium Zinc Telluride Charged Particle Nuclear Detectors}

\section{Introduction}

Cadmium Zinc Telluride (CZT) has many properties that make it well suited for use as a charged particle detector that can be operated at room temperature. These properties include the large atomic numbers of its constituent atoms ( $\mathrm{Z}=48,30$ and 52 for $\mathrm{Cd}, \mathrm{Zn}$ and $\mathrm{Te}$, respectively) which allows for a high stopping power to energetic charged particles, and a high bulk resistivity $\left(\sim 10^{11} \mathrm{~W}-\mathrm{cm}\right)$ which ensures a low dark current during detector operation. Although the potential of CZT for fabricating high-resolution charged particle detectors has been well demonstrated, there continue to be significant problems associated with carrier trapping, in which case the amount of charge collected is not a unique function of the particle energy. These transport problems have motivated considerable research into the electrical and optical properties that might be related to detector performance.

A chief concern related to the use of alloy materials for detector applications is degradation of detector resolution due to material non-uniformity. It has been shown that there is a correlation between uniformity of composition and detector resolution in CZT, and alpha particle response waveforms for CZT detectors often show slope changes that suggest a non-uniform electric field within the device. Ideally the pulse height should be proportional to the total charge produced, $Q$, the electric field, E, and the electron mobility, $\mathrm{m}_{\mathrm{e}}$. Observed pulses often have slope changes that suggests a discontinuity in either the mobility or the electric field. Our photocurrent mapping results presented below give confirmation of this field non-uniformity.

\section{Background}

Cadmium Zinc Telluride is a unique material from which nuclear radiation detectors can be fabricated that operate at room temperature and directly measure the number (detection) and energy (spectroscopy) of $\mathrm{x}$-ray and gamma-ray photons and charged 
particles that impinge on the detector. This capability in a room temperature detector allows for the production of portable handheld detector and spectrometer systems that may be operated for long periods of time in an unattended mode. DOE/Defense Programs have employed semiconductor radiation detectors fabricated in silicon or germanium for many years. These devices, while operating well in certain applications, require cryogenic cooling and are thus excluded from operation in a number of arenas vital to DOE/DP where portable compact spectrometers operating at room temperature are required. One of the leading candidate materials for operation at room temperature is cadmium zinc telluride. This capability allows for both the detection of the incident photon or particle as well as the identification of the atoms emitting the photons. Specific applications for the use of cadmium zinc telluride instruments include high sensitivity gamma-ray spectrometers that are used to locate nuclear materials by the Nuclear Emergency Search Team (NEST), the verification of nuclear materials in international safeguards, and the satellite detection of nuclear detonations or other radioactive releases. Gamma ray cameras that image nuclear material at gamma-ray energies and allow for the inspection of suspected enclosures without the need to gain access to the enclosure are also critical in arms control and treaty verification applications. Radiation monitors that are compact and hand held can be used for the monitoring of the movement of weapons-grade materials and to facilitate covert search operations. Sandia National Laboratories has projects to develop instruments suitable for many of these applications as well as for medical imaging, environmental remediation, nuclear safety, and basic science. The major obstacle to the widespread use of these devices has been the low manufacturing yield of a few percent of ultra-high resolution $x$ - and gamma-ray detectors and the resulting high cost of instruments based on these detectors.

\section{Models of Transport Phenomena}

Two types of models have been used to relate the photocurrent mapping data to material parameters. The first type is based on the Hecht relation which is routinely used to calculate charge collection efficiency in nuclear detectors. We have adapted the relation to 
photocurrent measurements and generalized it to the case of a nonuniform electric field. The second type of model is based on a general drift-diffusion equation.

The simplest way of relating charge collection efficiency to material parameters is via the Hecht relation[1]. This model gives the total charge collected when $\mathrm{N}_{0}$ electron-hole pairs are generated in a detector at a distance $x_{0}$ from the negative contact in terms of $(\mathrm{mt})_{e}$ and $(\mathrm{mt})_{\mathrm{h}}$, the mobility-lifetime products for electrons and holes respectively, the electric field, $\mathrm{E}$, which is assumed to be uniform, the thickness of the detector, d. Knoll and McGregor[2] have discussed the impact on the charge collection profile of unequal mobilitylifetime products. If, as is typical, $(\mathrm{mt})_{\mathrm{e}} \gg(\mathrm{mt})_{\mathrm{h}}$, maximum charge collection will be achieved if the charge is generated near the negative electrode, since in this case the holes travel only a short distance and the total charge collection is dominated by the electron contribution.

If the optical intensity is kept low to avoid space charge effects, the Hecht relation can be applied to cross-sectional photocurrent mapping by replacing $\mathrm{N}_{0}$, the number of electron-hole pairs generated by the interaction, by the number of absorbed photons per second. The expression for the photocurrent is:

$$
\left.I\left(x_{0}\right)=\frac{q E P_{a b s}}{d h v}\left[(\mu \tau)_{e}\left(1-e^{-\left(x_{0}-d\right) /(\mu \tau)_{e} E}\right)+(\mu \tau)_{h}\left(1-e^{-x_{g} /(\mu \tau)}\right)_{h}\right)\right]
$$

where $P_{a b s}$ is the absorbed optical power (assuming one electron-hole pair generated for each photon absorbed) and $\mathrm{hn}$ is the energy per photon. Figure 1 shows the predicted photocurrent vs. distance from the negative contact using typical parameters [3] for a $(\mathrm{Cd}, \mathrm{Zn}) \mathrm{Te}$ detector $2 \mathrm{~mm}$ thick. Equation (1) is based on the assumption that a charge carrier moving in an electric field $\mathrm{E}$ in a material where its mobility is $\mathrm{m}$ generates a current

$$
\mathrm{I}_{1}=\mathrm{qmE} / \mathrm{d}
$$

until it reaches the electrode and is collected, or until it recombines or is trapped. The charge collected due to $\mathrm{N}$ carriers as a function of time is then: 


$$
Q(t)=\frac{q \mu}{d} \int_{0}^{t} N\left(t^{\prime}\right) E\left(x\left(t^{\prime}\right)\right) d t^{\prime}
$$

Equation (1) follows for the case of a uniform electric field by assuming that the number of free electron-hole pairs varies with time due to recombination and trapping as

$$
N(t)=N_{0} \exp (-t / t)
$$

and integrating until the collection time - the time required for the carriers to reach the electrode.

The photocurrent for point excitation with an arbitrary electric field follows from equation (3) as:

$$
I=\frac{q P_{\text {abs }}}{d h v}\left(\mu_{e} \int_{0}^{t_{c, e}} e^{-t / \tau_{e}} E\left(x_{e}(t)\right) d t+\mu_{h} \int_{0}^{t_{c}, h} e^{-t / \tau_{h}} E\left(x_{h}(t)\right) d t\right)
$$

where $t_{c, e}$ and $t_{c, h}$ are the collection times for electrons and holes, respectively. The practical difficulty in applying this equation is that one must solve for the electron and hole trajectories - $x_{e}(t)$ and $x_{h}(t)$ before the integration can be performed. Closed-form solutions can be obtained only in a few simple cases. 


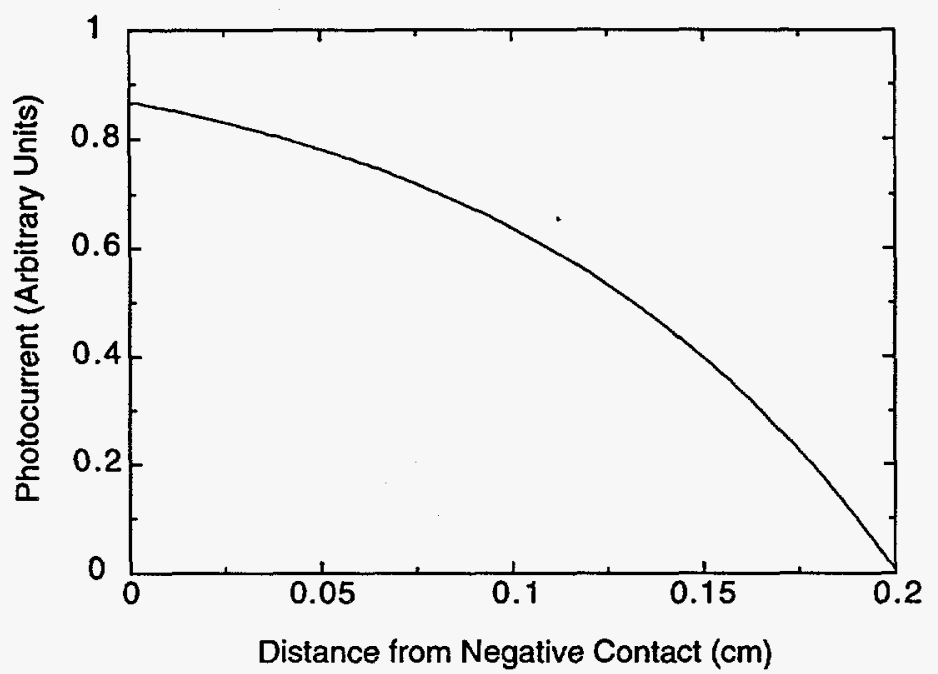

Figure 1: Photocurrent profile for a uniform electric field based on the Hecht relation, using typical parameters for $\mathrm{Cd}_{0.9} \mathrm{Zn}_{0.1} \mathrm{Te}:(\mathrm{mt})_{\mathrm{e}}=1.0 \times 10^{-3} \mathrm{~cm}^{2} / \mathrm{V},(\mathrm{mt})_{\mathrm{h}}=5.0 \times 10^{-6} \mathrm{~cm}^{2} / \mathrm{V}$, $\mathrm{E}=100 \mathrm{~V} / \mathrm{cm}, \mathrm{d}=0.2 \mathrm{~cm}$.

A more complete method of modelling transport phoenomena in bulk semiconductors is to use the general drift-diffusion equation [4]:

$$
\mathrm{dn} / \mathrm{dt}=\mathrm{G}+\mathrm{D}_{\mathrm{e}} \nabla^{2} n+\mu_{\mathrm{e}} E \cdot \nabla n-n / \tau_{\mathrm{n}}+\mu_{\mathrm{e}} \mathrm{n} \rho / \varepsilon
$$

where $G$ is the generation rate, $D_{e}$ is the diffusion coefficient for electrons, $\mathrm{n}$ is the density of free electrons and $\mathrm{r}$ is the space charge density. For the simplest case of steady-state conditions $(\mathrm{dn} / \mathrm{dt}=0)$ in a uniform electric field $(r=0)$, equation (5) gives a solution which is qualitatively similar to equation (1), as shown in Figure 2. Hence equation (1) can be used as an approximation.

\section{Photoconductivity Mapping Studies}

Photoconductivity mapping is performed by scanning a focused light source across the cleaved face of a detector which is held under bias and measuring the resulting photocurrent. In the studies 
described here an above-bandgap light source is used, so that the mechanism of charge carrier generation is photoelectric absorption, just as in detection of $\mathrm{x}$-rays or low-energy gamma rays. A typical two-dimensional photocurrent map for a $\mathrm{Cd}_{0.9} \mathrm{Zn}_{0.1}$ Te detector using $6328 \AA$ light from a He-Ne laser is shown in Figure 3. Lighter areas are those with higher photocurrent. As expected, the photocurrent is highest when the sample is illuminated near the negative contact.

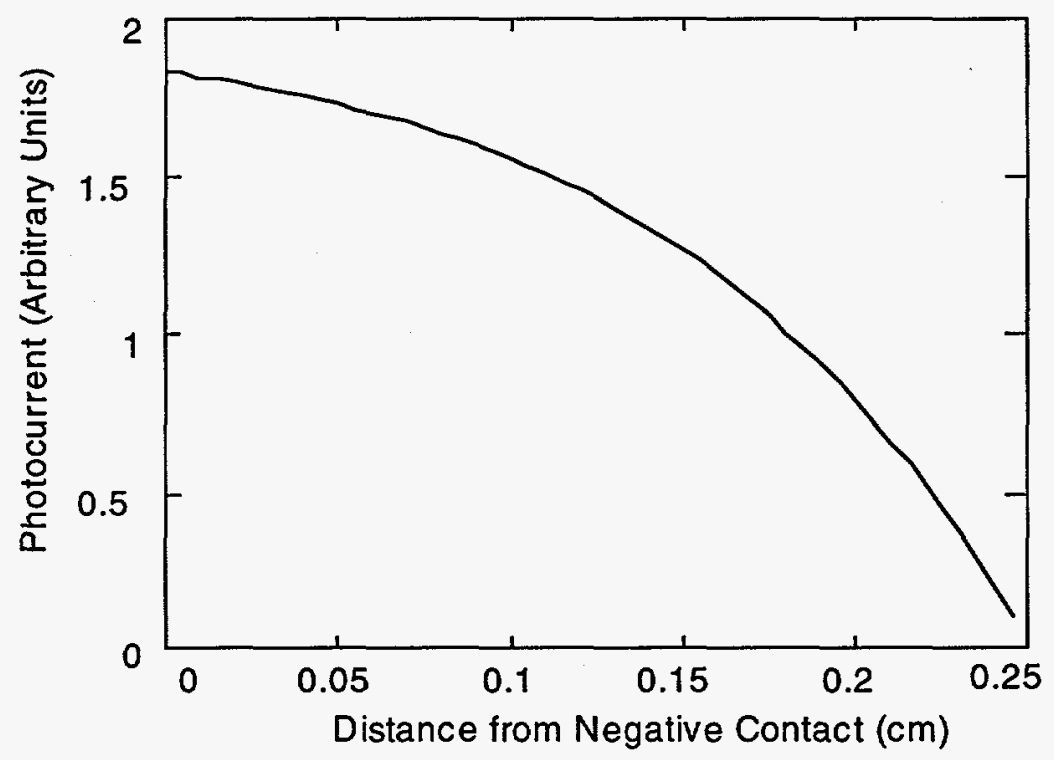

Figure 2: Photocurrent profile for a uniform electric field based on the drift-diffusion equation. Same parameters as in Figure 1.

Current (nA)
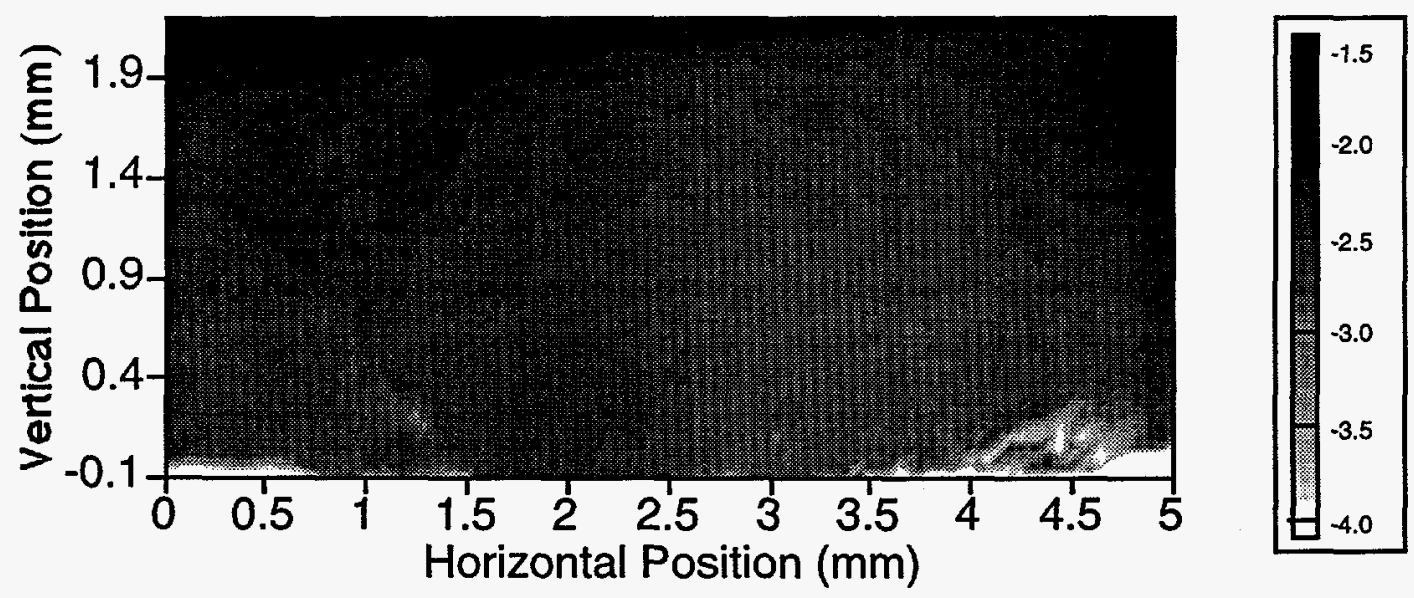

Figure 3: Two-dimensional photocurrent map using abovebandgap light. Brighter areas represent higher photocurrent. 
The nearly horizontal contours suggest a nearly uniform electric field. $1=6328 \AA$, incident power $=2 / 3 \mathrm{~mW}$, bias $=-30 \mathrm{~V}$ (top grounded), step size $=50 \mathrm{~mm}$.

Figure 4(a) shows a one-dimensional section through the twodimensional plot, along with a fit to the Hecht-type relation (1). A rough estimate for the electron mobility-lifetime product can be extracted from the data; the shape of the curve is too insensitive to the value of $(\mathrm{mt})_{\mathrm{h}}$ to allow that parameter to be determined. The oscillations of the data about the Hecht curve may indicate spatial fluctuations of the electric field, consistent with recently reported observations [5] based on the linear electro-optic effect. Figure 4(b) shows a second section from the same map which exhibits anomolously high photocurrent near the cathode, suggesting an increased electric field in that region.
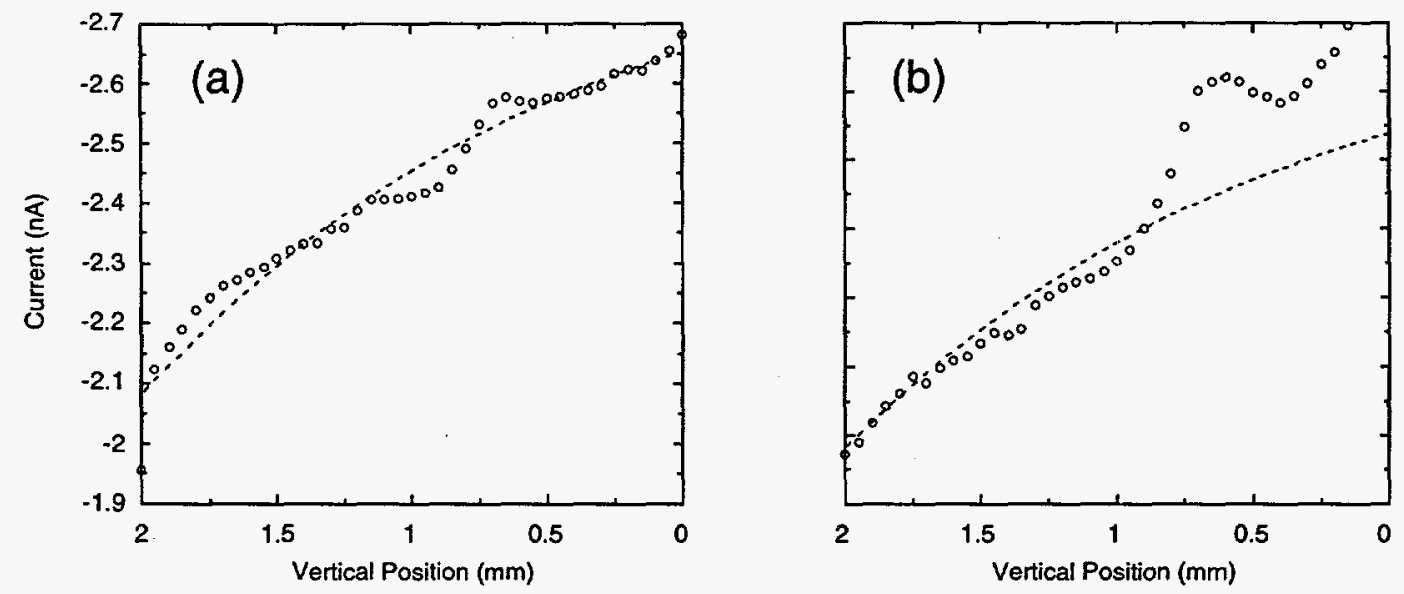

Figure 4: One-dimensional sections through a 2D photocurrent map. In (a) the curve shows oscillations about the normal Hecht-like curve, suggesting electric field fluctuations. In (b) the photocurrent increases substantially near the cathode, suggesting an enhanced electric field in that region. The dashed line is a fit using $(\mathrm{mt})_{\mathrm{e}}=1.3 \times 10^{-3} \mathrm{~cm}^{2} / \mathrm{V}$.

\section{Alpha Particle Response Studies}

Alpha particle response waveforms have been used to confirm the results of the photoconductivity mapping experiments. Figure 5 
shows typical electron pulses and their time derivatives from two spectrometer-grade detectors. Ideally the pulse height should be proportional to the amount of charge produced, the electric field, E, and the electron mobility, $\mathrm{m}_{\mathrm{e}}$. Since the transit time is typically much shorter than the electron lifetime, the exponential decay due to trapping of carriers is negligible. Each of the pulses shown here has a slope change that suggests a discontinuity in either the mobility or the electric field, similar to that which appears in Figure 4(b). These observations are similar to those recently reported by Luke and Eissler [6].

The value of $(\mathrm{mt})_{e}$ determined from Figure $4(\mathrm{a})$ is corroborated by alpha particle measurements which were performed on the same detector. Figure 6 shows the peak channel in the pulse height spectrum for ${ }^{244} \mathrm{Cm}$ alpha particles $(5.8 \mathrm{MeV})$ as a function of bias voltage. The alpha particles were incident on the negative contact so that electrons were the dominant charge carriers. The data has been fit to the time dependent form of the Hecht relation. A long shaping time was used, allowing $t$ to be replaced by the transit time, giving:

$$
Q(V)=\frac{q V N_{0}(\mu \tau)_{e}}{d^{2}}\left(1-e^{-d^{2} /(\mu \tau)_{0} v}\right)
$$

where $\mathrm{V}$ is the applied bias. Here it is assumed that the interaction occurs very near the surface so that the electrons travel the full width of the detector. The $(\mathrm{mt})_{\mathrm{e}}$ value determined from this fit is consistent with that determined from the photocurrent profile of Figure 4(a). 

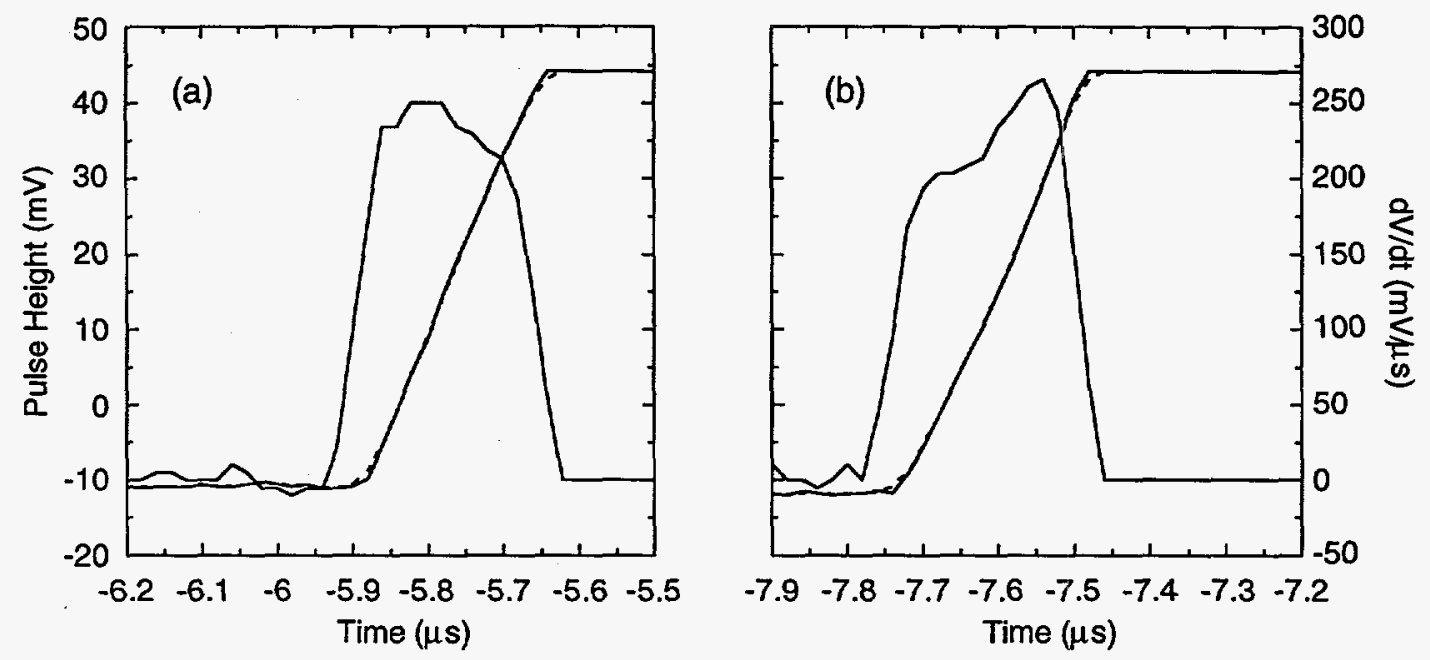

Figure 5: Alpha particle response pulses and their time derivatives. The alpha particles are incident on the negative contact, so that the response is due to electrons. In (a) the slope decreases gradually near the anode, while in (b) it increases abruptly near the anode. To reduce noise fluctuations, the derivative was based on a slightly smoothed version of the pulse data (dashed line). 


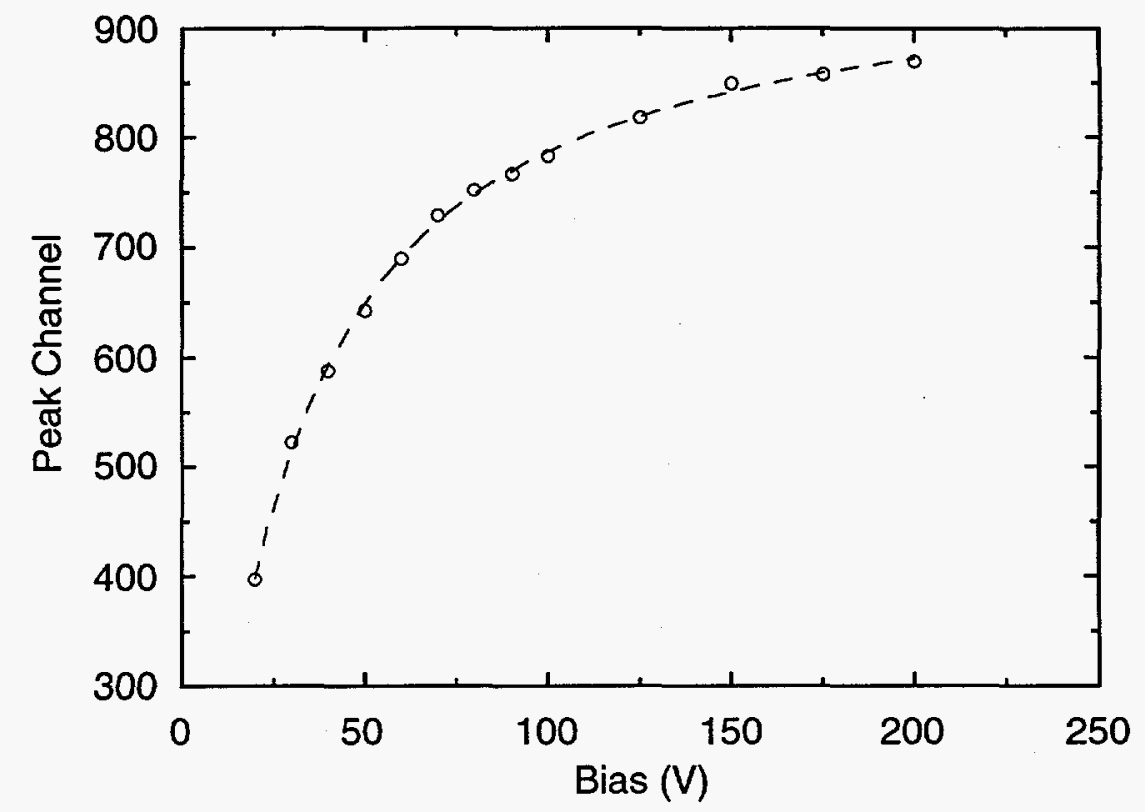

Figure 6: Charge collection as a function of bias voltage for alpha particle excitation, along with a fit to the Hecht relation. The $(\mathrm{mt})_{\mathrm{e}}$ value obtained is consistent with that obtained by photocurrent mapping.

Spatially resolved maps of alpha particle response rise times were also used to examine uniformity of detector performance. Figure 7 shows rise time maps for two detectors. The detector on the left has essentially uniform response, except for an increase in rise time near the edge of the contact, due to fringing of the electric field. The detector on the right has large areas in which the rise time is an order of magnitude higher than normal. The reason for this phenomenon can be seen by examining the response waveforms, shown in Figure 8. The high rise time regions have a short, sharp rise, followed by a long, slow exponential. This waveform is characteristic of de-trapping. Hence this rise time map can be taken as a map of trapping centers, possible grain boundaries in this case. 

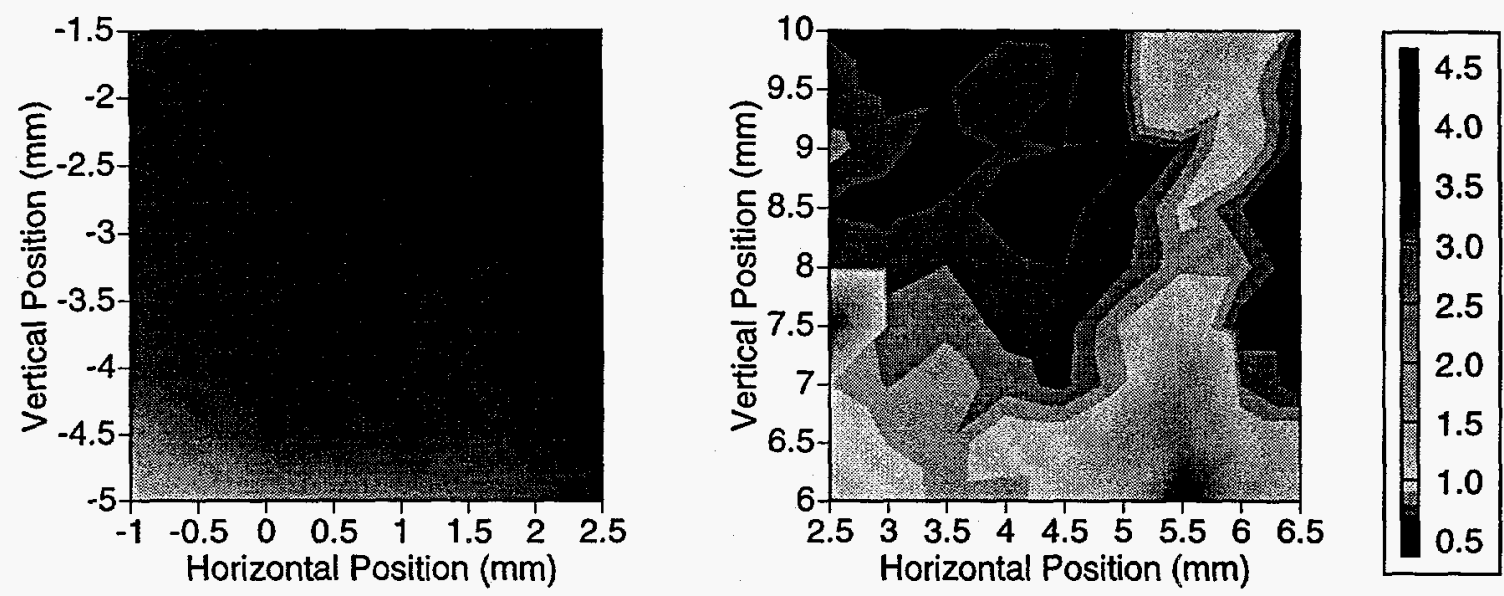

Figure 7 : Alpha particle response rise time maps for two detectors. The detector on the left has regions of anomalously high rise time which appear to be due to de-trapping phenomena (see Figure 8). The scale is rise time in microseconds.
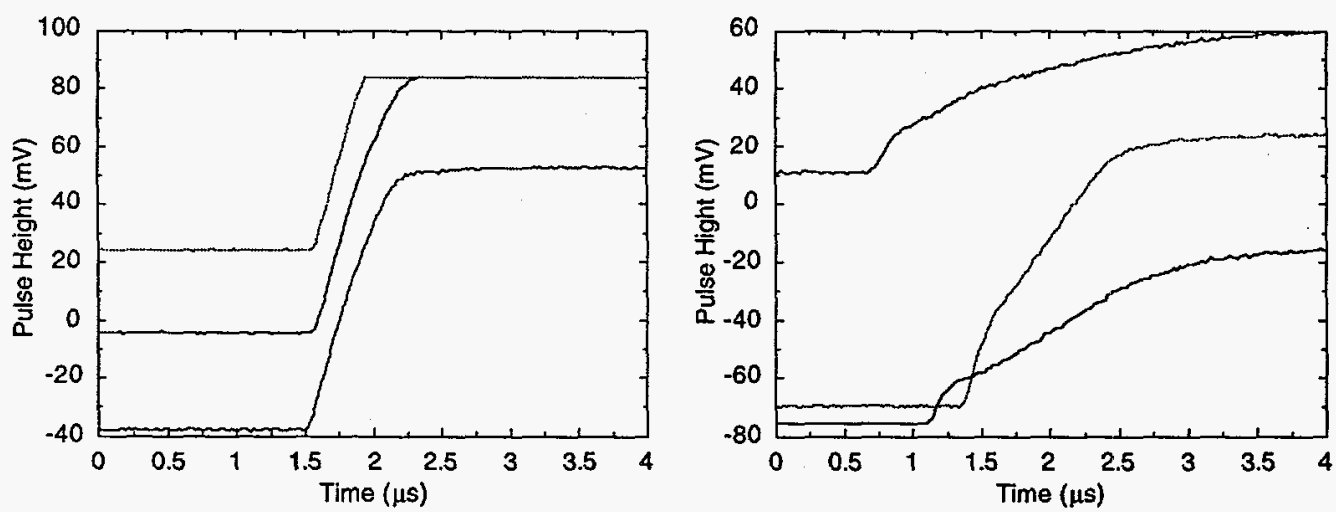

Figure 8: Typical alpha particle response waveforms from normal (left) and slow (right) regions of the detector on the right in Figure 7. The slow regions show a long, exponential rise characteristic of de-trapping. 


\section{Conclusions}

The state of the art in spectrometers and detectors employing cadmium zinc telluride has been advanced markedly. In addition, the understanding of the approaches that will be fruitful in overcoming barriers to further improvement of this material and these detectors has been made clear. These approaches include improving the material to reduce hole trapping, producing devices that rely only on the electron transport, and developing electronic means to compensate for the effects of incomplete charge collection.

Sandia National Laboratories now maintains active research collaborations with a number of industrial and academic institutions which have grown out of this as well as other efforts related to this technology. A recent workshop on this topic hosted by Sandia (California) included over seventy participants representing most of the country's organizations who are currently working in this technology area. These interactions have allowed Sandia National Laboratories to effectively leverage the efforts it maintains in this field. 


\section{References}

1. K. Hecht, Z. Physik (1932), 235.

2. G. F. Knoll and D. S. McGregor,"Fundamentals of Semiconductor Detectors for Ionizing Radiation," in Semiconductors for Room Temperature Radiation Detector Applications, R. B. James, P. Siffert, T.E. Schlesinger and L. Franks eds. MRS Symp. Proc. 302 (1993) pp. 3-17.

3. M. Squillante and K. Shah, "Other Materials: Status and Prospects," in Semiconductors for Room-Temperature Nuclear Detector Applications, T.E. Schlesinger and R.B. James eds. (Academic,1995) p. 470.

4. R.N. Bube, Photoelectronic Properties of Semiconductors (Cambridge, 1992) p. 40.

5. P. De Antonis, E.J. Morton and F.J.W. Podd, "Infra-red Microscopy of (Cd,Zn)Te Radiation Detectors Revealing Their Internal Electric Field Structure Under Bias," IEEE Trans. Nucl. Sci. 43 (1996) 1487.

6. P. N. Luke and E. Eissler, "Performance of $(\mathrm{Cd}, \mathrm{Zn}) \mathrm{Te}$ Coplanar-Grid Gamma-Ray Detectors," IEEE Trans. Nucl. Sci. 43 (1996) 1481. 
UNLIMITED RELEASE

INITIAL DISTRIBUTION:

Richard Malenfant

U.S. Department of Energy

Office of Research and Development, NN-20

1000 Independence Avenue, S.W.

Washington, D.C. 20585

Eric Bragg

ORD/CTG/COTD

754 Ames

Washington, D.C. 20505

T. E. Schlesinger (2)

Department of Electrical and Computer Engineering

Carnegie Mellon University

Pittsburgh, Pennsylvania 15213

A. Burger

Department of Physics

Fisk University

Nashville, Tennessee 37208

M. Roth

Graduate School of Applied Science

Hebrew University of Jerusalem

Jerusalem, Israel 91904

Y. C. Chang

Department of Physics

University of Illinois

1110 West Green Street

Urbana, Illinois 61801 
Department of Materials Science and Engineering

Attn: M. Goorsky

Hojun Yoon

University of California at Los Angeles

Los Angeles, California 90095-1595

Glenn Knoll

Dean, College of Engineering

University of Michigan

2309 EECS Building

Ann Arbor, Michigan 48109-2116

H. Yao

Department of Electrical Engineering

University of Nebraska

Lincoln, Nebraska 68588

DigiRad

Attn: Jack Butler (2)

Patrick Doty (2)

7408 Trade Street

San Diego, California 92121-2410

Jack Trombka

Senior Goddard Fellow

Goddard Space Flight Center

MC 691, Bldg. 2, Rm. 235

Greenbelt, Maryland 20771

Bob Scarlett

Los Alamos National Laboratory

MS D460

Los Alamos, New Mexico 87545

Warnick Kernan

Remote Sensing Lab

4600 N. Hollywood Blvd., Bldg. 2211

Las Vegas, Nevada 89191

MS0121 V. Portillo 


\begin{tabular}{|c|c|}
\hline MS0459 & J. M. Taylor \\
\hline MS0471 & D. L. Mangan \\
\hline MS0571 & R. L. Ewing \\
\hline MS0571 & R. Moya \\
\hline MS 1380 & D. Lambert (3) \\
\hline MS 1380 & D. S. Rix \\
\hline MS 1380 & D. W. Larson \\
\hline MS 1380 & R. Calvert \\
\hline MS 1425 & R. C. Hughes \\
\hline MS9001 & T. O. Hunter \\
\hline & $\begin{array}{l}\text { Attn: P. Smith, MS9002 } \\
\text { D. Crawford, MS9003 } \\
\text { M. John, MS9004 } \\
\text { J. Wright, MS9005 } \\
\text { R. Wayne, MS9007 } \\
\text { B. McLean, MS9054 } \\
\text { P. Brewer, MS9141 } \\
\text { M. Dyer, MS9405 }\end{array}$ \\
\hline MS9007 & A. Pontau \\
\hline MS9056 & J. Vitko \\
\hline MS9141 & A. Freudendahl (2) \\
\hline MS9161 & D. Cowgill \\
\hline MS9161 & J. Markakis \\
\hline MS9161 & J. VanScyoc \\
\hline MS9161 & M. Schieber (2) \\
\hline MS9161 & R. J. Anderson \\
\hline MS9162 & L. Franks \\
\hline MS9402 & A. Antolak \\
\hline MS9402 & D. Medlin \\
\hline MS9402 & D. Morse \\
\hline MS9403 & J. C. F. Wang \\
\hline MS9404 & E. Soria \\
\hline MS9405 & J. Hruby \\
\hline MS9405 & J. C. Lund \\
\hline MS9405 & R. B. James (4) \\
\hline MS9409 & R. Stulen \\
\hline
\end{tabular}




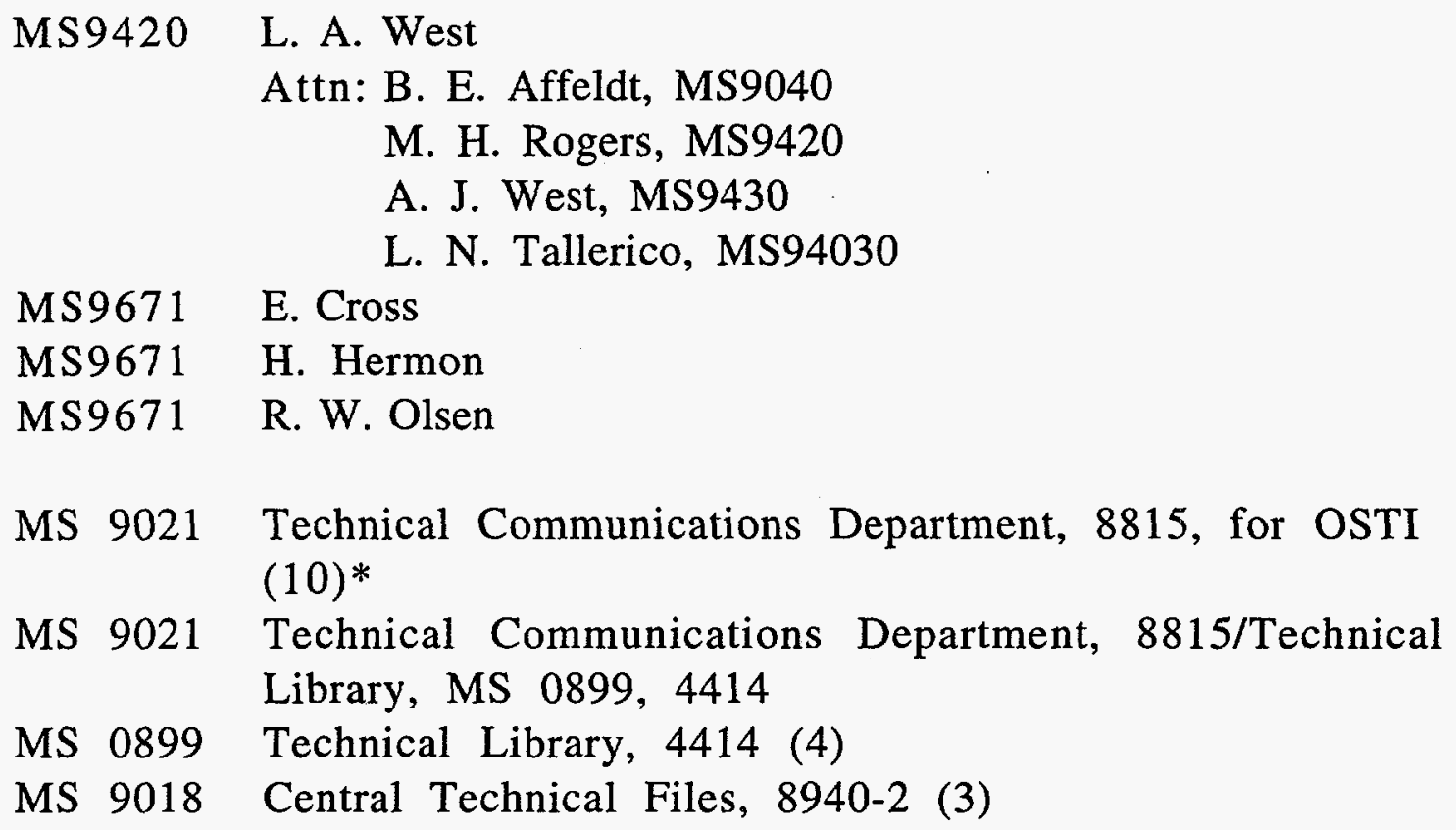

MS 9021 Technical Communications Department, 8815, for OSTI (10)*

MS 9021 Technical Communications Department, 8815/Technical Library, MS 0899, 4414

MS 0899 Technical Library, 4414 (4)

MS 9018 Central Technical Files, 8940-2 (3) 